In univariate analysis, presence of EAMs in AS was associated with significantly higher disease activity, BDI total score, WLQ mental interpersonal demands (only for $E_{A M_{1} 1}$ ), WLQ physical demands, WLQ time demands, SF-12 physical function, SF-12 role physical, SF-12 bodily pain, SF-12 vitality, SF-12 mental health (only for $E_{A M}$ ), and the SF-12 physical component summary score (PCS). Among PsA patients, patients with $\mathrm{EAM}_{\mathrm{PsA}_{\mathrm{A}}}$ had higher disease activity but no significant association was observed between EAMPsA and PROs.

Upon adjusting for disease state, disease type, and ever smoking, presence of $E_{A M_{1} /} / E A M_{P s A}$ for AS/PsA patients was associated with significantly higher BDI total score (14.0 vs. 12.6, $\mathrm{p}=0.046$ ) and lower SF-12 physical function (38.4 vs. $44.8, p=0.047)$. When evaluating the impact of $E A M_{A S 2} / E A M_{P s A}$ for $A S / P s A$ patients no significant differences were observed in PROs; however, BDI was notably higher among patients with EAMs (14.1 vs. 12.7, $\mathrm{p}=0.056$ ).

Conclusions: In a Canadian routine clinical care setting, a substantial proportion of $A S$ and PsA patients requiring a change in treatment report EAMs. Presence of EAMs, particularly psoriasis for AS patients, was found to be a significant independent predictor of depressive symptoms and reduced quality of life due to worse physical functioning.

Acknowledgements: JSS Medical Research, Montreal, Canada

Disclosure of Interest: L. Bessette Consultant for: Amgen, BMS, Janssen, Roche, UCB, AbbVie, Pfizer, Celgene, Lilly, Novartis, Speakers bureau: Amgen, BMS, Janssen, Roche, UCB, AbbVie, Pfizer, Merck, Celgene, Lilly, Novartis, M. Khraishi Consultant for: AbbVie, Speakers bureau: AbbVie, B. Florica Consultant for: for Roche, Abbvie, Pfizer, Janssen, Celgene, UCB, Speakers bureau: Janssen, Merck, Abbvie, Roche, BMS, Novartis, Y. Setty Consultant for: AbbVie, M. Teo Consultant for: AbbVie, Amgen, Celgene, Janssen, Merck, Novartis, Pfizer, Roche, Sanofi-Genzyme UCB, Speakers bureau: AbbVie, Roche, V. Remple Shareholder of: AbbVie, Employee of: AbbVie DOI: 10.1136/annrheumdis-2018-eular.3797

\section{THU0265 PATIENTS WITH AXIAL SPONDYLOARTHRITIS RARELY HAVE 1 OR 2 INFLAMMATORY BACK PAIN PARAMETERS}

M. de Hooge ${ }^{1,2}$, G.V. Varkas ${ }^{1,2}$, D. Elewaut ${ }^{1,2}$, F. van den Bosch ${ }^{1,2}$.

${ }^{1}$ Rheumatology, Ghent University Hospital; ${ }^{2}$ VIB Inflammation Research Centre, Ghent University, Gent, Belgium

Background: The Berlin Algorithm is a tool that assists clinicians in diagnosing axial spondyloarthritis (axSpA). In the modified Berlin Algorithm inflammatory back pain (IBP) is excluded as entry criterion. Although the modified Berlin Algorithm is used in clinical practice some argue that this modification insufficiently emphasises the inflammatory character of axSpA.

Objectives: The study aim was to provide an overview of the IBP parameters present in axSpA patients included in the Be-Giant cohort.

Methods: Data of an observational multicentre cohort study was used. Patients aged $\geq 18$ years with a new axSpA diagnosis and fulfilling the ASAS axSpA criteria were included in the Belgian inflammatory arthritis and spondylitis cohort (Be-Giant). All 5 IBP parameters used in the ASAS axSA classification criteria were collected during the clinical visit to the outpatient clinic. IBP parameters collected were: 1) Age at onset $<40$ years, 2) insidious onset, 3 ) improvement with exercise, 4) no improvement with rest and 5) pain at night. IBP is defined when $\geq 4$ of these parameters are present. Besides these 5 parameters also 'alternating buttock pain' and 'morning stiffness' are reported as these parameters are part of other IBP criteria then the ASAS criteria. All descriptive data was presented as $n(\%)$ or means $( \pm S D)$.

Results: All IBP parameters were collected from 228 patients and $49.6 \%(n=113)$ was male with mean age of 34.7 years (SD 9.7). Individual parameters were present in $>75 \%$ of the patients; the parameter 'age at onset $<40$ years' was present in $95.2 \%$, 'insidious onset' in $89 \%$, 'improvement with exercise' in $86 \%$, 'no improvement with rest' in $81.6 \%$ and 'pain at night' in $75.9 \%$ of the patients. There were 83 patients (36.4\%) with alternating buttock pain and 173 patients (75.9\%) with morning stiffness.

More than $80 \%$ of the patients (183/228) had IBP according to the ASAS criteria as they had $\geq 4$ IBP parameters. Patients rarely had 1 or 2 IBP parameters; $2(0.9 \%)$ patients with 1 parameter and $12(5.3 \%)$ patients with 2 parameters (table 1$)$.

Abstract THU0265 - Table 1. Total number of ASAS-IBP parameters in patients with axSpA diagnosis and classified according to the ASAS criteria in the Be-Giant cohort.

\begin{tabular}{lc}
\hline & Be-Giant cohort $\mathbf{n = 2 2 8}$ \\
\hline 0 IBP parameters & 0 \\
1 IBP parameters & $2(0.9 \%)$ \\
2 IBP parameters & $12(5.3 \%)$ \\
3 IBP parameters & $31(13.6 \%)$ \\
4 IBP parameters & $59(25.9 \%)$ \\
5 IBP parameters & $124(54.4 \%)$ \\
\hline IBP, inflammatory back pain. & \\
IBP parameters: Age onset back pain $<40$ years, insidious onset of back pain, improvement \\
with exercise, no improvement with rest, pain at night.
\end{tabular}

Conclusions: The majority of early axSpA patients had $\geq 4$ IBP parameters and therefore fulfilled the ASAS IBP criteria. A minority shows 1 or none IBP parameter. Hence, the inflammatory character of axSpA does not seem to subverted now that IBP is not a mandatory feature in classification of axSpA.

Disclosure of Interest: None declared

DOI: 10.1136/annrheumdis-2018-eular.4925

\section{THU0266 THE VALUE OF BELONGING TO PATIENTS' ASSOCIATION FOR AXIAL SPONDYLOARTHRITIS: RESULTS FROM THE ATLAS-2017}

M. Garrido-Cumbrera ${ }^{1,2}$, D. Gálvez-Ruiz ${ }^{1}$, E. Collantes Estevez ${ }^{3,4}$, C. Blanch Mur ${ }^{5}$ V. Navarro-Compán ${ }^{6} .{ }^{1}$ Universidad de Sevilla, Sevilla; ${ }^{2}$ CEADE, Madrid;

${ }^{3}$ Medicina, Universidad de Córdoba; ${ }^{4}$ Rheumatology, Hospital Universitario Reina

Sofía, Cordova; ${ }^{5}$ Novartis, Barcelona; ${ }^{6}$ Rheumatology, Hospital Universitario La

Paz, IdiPaz, Madrid, Spain

Background: International guidelines suggest that patients with axial spondyloarthritis (axSpA) become members of patient associations and self-help groups. However, the scientific evidence for this advice is limited and poor.

Objectives: To assess the relationship between membership of axSpA patient associations with regard to physical and psychological outcomes of the disease.

Methods: A sample of 680 axSpA patients was interviewed as part of the Spanish-2017 Atlas, which aimed to promote early referral, improve healthcare, and the use of effective treatments in patients with axSpA. By means of an online survey, the following self-reported data were collected: sociodemographic, smoking habits, degree of functional limitation in 18 daily activities (graded from 0-3 as none, little, some, moderate), spinal stiffness level at cervical, thoracic, and lumbar spine (0-3 none, little, some, moderate), disease activity through BASDAI (010), risk of severe psychiatric illness using General Health Questionnaire - GHQ$12(0-12)$, and treatment received (NSAIDs and biological therapy). Differences for all these variables between associated-patients and non-associated patients were tested, using Mann-Whitney or Chi-square tests.

Results: Out of 680 patients, $301(44.3 \%)$ were members of patient associations. Compared to non-associated patients, those associated were older, more fre quently male, married, and few smoked (table 1). Additionally, despite having longer disease duration and receiving similar treatment, associated patients had lower disease activity (BASDAI 5.1 vs $5.8 ; p=0.001$ ), less functional limitation ( 26.5 vs $28.7 ; p<0.05$ ), and less risk of severe psychiatric illness (GHQ-12 4.9 vs $6.5 ; p<0.001)$

Abstract THU0266 - Table 1. Characteristics stratified by patient association membership status

\begin{tabular}{|c|c|c|c|}
\hline & $\begin{array}{c}\text { Associated } \\
\text { (mean } \pm \text { SD or } \\
\%)\end{array}$ & $\begin{array}{c}\text { Non-Associated } \\
\text { (mean } \pm \text { SD or } \\
\%)\end{array}$ & $P$ \\
\hline Age (years) & $49.7 \pm 11.2$ & $42.4 \pm 9.4$ & $<0.001$ \\
\hline Gender (Male) & $57.8 \%$ & $39.3 \%$ & $<0.001$ \\
\hline Education Level (University) & $34.6 \%$ & $38.8 \%$ & 0.3 \\
\hline Marital Status (Married) & $79.1 \%$ & $65.4 \%$ & $<0.001$ \\
\hline Smoker & $32.6 \%$ & $41.6 \%$ & $<0.01$ \\
\hline Disease duration (years) $(n=555)$ & $26.0 \pm 12.4$ & $17.0 \pm 10.3$ & $<0.001$ \\
\hline $\begin{array}{l}\text { HLA-B27 (Positive) ( } \mathrm{n}=558) \\
\text { Treatment }\end{array}$ & $79.7 \%$ & $74.9 \%$ & 0.097 \\
\hline - NSAIDs (without biology) & $28.6 \%$ & $30.9 \%$ & 0.5 \\
\hline $\begin{array}{l}\text { - Biological (monotherapy or with } \\
\text { NSAIDs) }\end{array}$ & $39.2 \%$ & $34.0 \%$ & 0.2 \\
\hline BASDAI $(0-10)(n=442)$ & $5.1 \pm 2.1$ & $5.8 \pm 2.1$ & 0.001 \\
\hline $\begin{array}{l}\text { Stiffness } \\
\text {-Without Stiffness - low } \\
\text { - mild }\end{array}$ & $10.2 \%$ & $11.2 \%$ & $<0.01$ \\
\hline - high & $\begin{array}{l}17.6 \% \\
27.8 \% \\
44.5 \%\end{array}$ & $\begin{array}{l}20.0 \% \\
38.6 \% \\
30.2 \%\end{array}$ & \\
\hline $\begin{array}{l}\text { Functional Limitation } \\
(0-54)(n=605)\end{array}$ & $26.5 \pm 13.4$ & $28.7 \pm 12.9$ & 0.038 \\
\hline GQH-12 $(0-12)(n=474)$ & $4.9 \pm 4.5$ & $6.5 \pm 4.4$ & $<0.001$ \\
\hline
\end{tabular}

Conclusions: In axSpA, belonging to patient associations is related to better physical and psychological outcomes. Accordingly, rheumatologists should encourage patients to join these groups. However, further data on longitudinal studies is required to confirm these results.

Acknowledgements: The Atlas was promoted by CEADE and funded by Novartis

Disclosure of Interest: M. Garrido-Cumbrera: None declared, D. Gálvez-Ruiz: None declared, E. Collantes Estevez: None declared, C. Blanch Mur Employee of: Novartis, V. Navarro-Compán: None declared DOI: 10.1136/annrheumdis-2018-eular.7216 